\title{
A Pilot Project to Develop Checklist-Based Recommenda- tions on the Requirements for Clinical Cancer Research Centers in Countries with Limited Resources
}

\author{
Alexandru Eniu \\ Department of Breast Tumors, Cancer Institute 'I. Chiricuta', Cluj-Napoca, Romania
}

\section{Key Words}

Breast cancer · Clinical research - Limited resources

\section{Summary}

Clinical studies are the only controlled way of comparing a new treatment to existing standards. Unfortunately, less than $5 \%$ of patients in developed countries are enrolled in clinical trials, thus strongly limiting the possibility of answering important clinical questions. Large numbers of cancer patients are treated in countries with limited resources (CLR). Here, cancer centers that are able to provide good standard of care are capable of contributing by enrolling large numbers of eligible patients into clinical trials. We present a pilot project aimed at developing a set of checklists that include all elements of infrastructure, equipment, staff, and training that a center should possess in order to enroll patients into phase II, III, and IV clinical trials. These elements will be stratified in an incremental list to contain essential, desirable, and optional items. Also, requirements for staffing and training of research staff will be developed. The development of a continuous audit program will be proposed to ensure quality control, and each potential trial center will undergo an initial audit to evaluate its suitability. The checklists may also serve as a guide for centers wishing to participate in clinical trials. The ultimate goal of this project is to increase the number of trial centers in CLR for the benefit of patients, science, and society in general.

\section{Introduction}

Improvements in the care of cancer patients can only be achieved through the use of clinical trials, by generating evi-
Schlüsselwörter

Brustkrebs · Klinische Forschung · Beschränkte Mittel

\section{Zusammenfassung}

Klinische Studien sind der einzige kontrollierte Weg, um neue Therapien mit existierenden Standards zu vergleichen. Leider werden in entwickelten Ländern weniger als $5 \%$ der Patienten in klinische Studien aufgenommen, was die Beantwortung wichtiger klinischer Fragen stark behindert. Eine große Anzahl an Krebspatienten wird in Ländern mit beschränkten finanziellen Mitteln behandelt. Hier leisten gut ausgestatte Krebszentren einen großen Beitrag, indem sie eine Großzahl geeigneter Patienten in klinische Studien aufnehmen. Wir stellen ein Pilotprojekt vor, das zum Ziel hat, eine Sammlung an Checklisten zu erstellen, die alle Elemente bezüglich Infrastruktur, Austattung, Personal und Ausbildung eines zur Durchführung von Phase-II-, -III- und -IV-Studien geeigneten Krebszentrums umfasst. Diese Elemente sollen in essentielle, wünschenswerte und optionale Aspekte eingeteilt werden. Außerdem sollen Anforderungen an die Besetzung von Forschungsstellen und die damit verbundene Ausbildungen definiert werden. Weiterhin werden wir die Entwicklung eines fortlaufenden Programms zur Qualitätskontrolle vorschlagen, und jedes potentielle Studienzentrum soll einer initialen Eignungsprüfung unterzogen werden. Die Checklisten könnten außerdem als ein Leitfaden für Zentren dienen, die an klinischen Studien teilnehmen möchten. Das ultimative Ziel dieses Projektes ist es, die Anzahl an Studienzentren in Ländern mit beschränkten Mitteln zu erhöhen, und somit den Patienten, der Wissenschaft sowie der Gesellschaft zu dienen.

dence-based data that can then be used in clinical practice. Clinical studies are the only accepted method by which a promising new treatment can be evaluated in a controlled way against existing standards. All methodological and ethical as-

\begin{tabular}{|c|c|}
\hline KARGER & (c) 2008 S. Karger GmbH, Freiburg \\
\hline $\begin{array}{l}\text { Fax +49761 } 4520714 \\
\text { E-mail Information@Karger.de } \\
\text { www.karger.com }\end{array}$ & $\begin{array}{l}\text { Accessible online at: } \\
\text { www.karger.com/brc }\end{array}$ \\
\hline
\end{tabular}


pects of clinical research are highly regulated to ensure that the rights of the patients are not altered and that standardized, best clinical practice is uniformly used for the enrolled patients. Current clinical practice is based on the results of international, multicenter clinical studies conducted in developed countries like the US, Canada, and Western Europe. Despite data showing that more than a third of adult cancer patients have a positive attitude towards participation in a clinical trial, less than $5 \%$ of potentially eligible patients are enrolled in trials in these countries [1]. The reasons for this situation, which is expected to last, are multiple, including better prognosis of patients, broad availability of effective state of the art treatments, lack of interest from both the patients and the medical staff, etc. This limits the possibility of addressing important clinical questions to which an answer is imperiously needed.

Large numbers of cancer patients are treated each day in countries with limited resources (CLR). The existing limitations in CLR lead to diversity in the level of cancer care provided [2]; the medical staff is hampered by the lack of certain equipment, but is striving to provide best care with limited resources. Although great heterogeneity exists in such countries among the units that treat cancer patients, centers can be identified that are able to provide good standard of care. These centers are capable of contributing by enrolling large numbers of eligible patients into clinical trials, provided they can comply with the trial requirements.

\section{Specific Aims}

There are no published guidelines for setting up a clinical research center in CLR. Our project intends to fill this gap by providing specific checklist recommendations. The purpose of this project is to develop a set of checklists that include all elements of infrastructure, equipment, staff, and training that a center should have in order to enroll patients into phase II, III, and IV clinical trials. The specific aims of this project are, but not limited to, the following: i) devise complete checklists of needed infrastructure, equipment, and staff stratified in essential, desirable, and optional items; ii) describe requirements for training of research staff; iii) develop core curriculum descriptions for training of research staff; iv) create standard operating procedure manuals (SOPs); v) develop a continuous audit program to ensure quality control.

\section{Project Design}

An analysis of the current regulations and requirements governing the conduct of clinical studies will be performed. Good clinical practice guidelines will be reviewed in all aspects related to enrollment of subjects in clinical trials: informed consent process, initial evaluations, target lesions identification and follow-up, toxicity assessment, serious adverse events reporting, etc. Requirements issued by various collaborative groups and clinical research organizations for initial qualification of potential new centers for phase II, III, and IV clinical studies will also be analyzed. We deliberately excluded from our analysis phase I studies, as these have highly specialized requirements (usually not met in CLR) to enroll small number of patients. An incremental matrix checklist will then be constructed, listing essential, desirable, and optional items. For instance, for diagnostic equipment, an essential piece of equipment might be an X-ray machine and an ultrasound, desirable will be a conventional computed tomography (CT) scanner, while optional will be a helical CT scanner. In terms of communication infrastructure, for example, a telephone is essential, a fax machine is desirable, and internet access is ideal. The draft of the checklist will then be debated with collaborators, including clinical investigators with a vast experience in the conduct of clinical trials, to ensure that all areas have been adequately covered. After discussions, the final checklist will be elaborated; it will have 4 columns and 3 rows. The columns will be dedicated to infrastructure, equipment, staff, and training. The rows will list essential, desirable, and optional elements for each of the 4 columns, including confidentiality and ethical concerns that need to be met by the center. Additionally, a section of the checklist will be dedicated to estimate the potential of accrual, in patients per year, for different stages of disease, based on local incidence and addressability. In implementing clinical studies, special attention is needed to identify the elements of considered part of the standard of care for any patient, whose costs remain the responsibility of the treating center, versus special requirements imposed by the design of the study (e.g. more frequent blood or imaging tests) that are covered by the sponsor. Another chapter will describe the core curriculum requirements for training of the research staff, in terms of the outside training courses and also on-site syllabi and teaching aids that need to be available for each category of staff (physicians, co-investigators, research nurses, study coordinators, data managers, etc.). For the continuing professional development of the existing staff, evidence-based and resource-appropriate guidelines must be available and in use for the treatment of common cancers, preferably based upon research done locally or in similar settings. Another section will describe the process of creating SOP manuals for various situations encountered during the conduct of a clinical study. Examples will be provided to facilitate the development of local SOP adapted to the local situation that will ensure proper action is taken in front of a specific situation. Finally, for measuring, monitoring, and improving on a regular basis the quality of treatment delivered in the setting of a clinical study - as well as outside the study -, the development of a continuous audit program will be described to ensure quality control. A system of available and in use robust tools for clinical audits (along with administrative mechanisms for rewarding those persons doing a good job, and helping and/or punishing those not doing such a good job) will be devised. 


\section{Confidentiality and Ethical Considerations}

Confidentiality is a major prerequisite for the handling of medical data, and it includes but is not limited to patients enrolled in clinical studies. One of the aims of the recommendations will be to ensure that the standard procedure of blinding all patient personal identification data outside the medical team is implemented. During data collection in the Case Report Forms, patients are identified using their initials and a patient number assigned at the inclusion in the study, ensuring patients privacy. From the ethical point of view, all clinical studies undergo a thorough evaluation in order to be approved by several ethics committees prior to being implemented in the clinic. Specific recommendations will be made to create institutional or national ethics committees to analyze and approve or reject all clinical studies.

\section{Target Groups}

The first target group is represented by cancer patients from CLR: by providing access to clinical trials made available in their local center/country, cancer patients will benefit by having access to best medical practice as imposed by the clinical studies. Although much of the costs of delivering cancer care remain the responsibility of the treating center, participating in phase III clinical trials, in which often the standard arm therapy is also supported by the sponsor, may be the only possibility in some countries to have access to state of the art but expensive treatments, such as targeted therapies, thus providing direct benefit for the patients due to free access to standard-of-care expensive treatment.

The second target group is represented by clinical researchers and decision makers in CLR: the checklist recommendations will serve as guidelines for centers wishing to participate in clinical trials and plan the development of their unit by acquiring missing elements, allowing self-evaluation for those centers interested in joining a research network. Participation in clinical trials will also lead to improvement in the general care standard due to education of the staff and implementation of good clinical practice principles.

The third target group is represented by sponsors of clinical cancer research: collaborative groups, National Cancer Institute (NCI)-like organizations, and pharmaceutical companies seeking new centers to enroll patients: the guidelines provide a complete and simple evaluation of a center for potential participation in a clinical study.

\section{Critical Assessment and Possible Limitations}

Due to different curricula in countries throughout the world, the training of the members of the research team (investigators, research nurses, data managers, etc.) will not be identical among countries. We hope that, by describing the core curricula, the educational needs of each team member will be identified and fulfilled. The importance of clinical cancer research is not always well understood in CLR. Usually, the scarce resources are directed towards approved diagnostic and treatment solutions, as clinical research is seen as a way of wasting resources without having the certitude of a benefit. This situation can lead to difficulties in implementing the recommendations for clinical research. We believe that a clear discussion of the potential benefits of participating in a clinical study, both for the patient and for society can change this misconception in those centers with motivated investigators.

\section{Expected Results and Potential of Applicability}

The expected outcome of this project is a high quality article that will contain the checklist-based set of recommendations of infrastructure, equipment, personnel, and training needed to perform phase II, III, and IV clinical trials. The checklists will constitute a useful tool for assessing the capabilities of different centers to participate in clinical studies. It will provide a simple and rapid way to evaluate the existing facilities, and to identify missing elements that need to be acquired to make a center eligible. It can be used both internally, to help managers plan the development of their unit, and externally by thirdparty clinical research organizations seeking new candidate centers for clinical studies. The benefits derived from the use of the checklist are multiple. The first to benefit will be the patients in CLR that will have the opportunity to participate in clinical studies and have access to state-of-the-art treatment. The medical professionals will also benefit by improving their skills through education and more rigorous compliance with the good clinical practice principles. Participation in clinical studies will bring international visibility for the institution and the investigators, and also direct financial benefits. Increasing the accrual in clinical studies will advance our knowledge and science, this benefiting the society in general. Once validated by their use in practice, the checklists can then be adapted and extended to other areas of clinical research. The methodology of clinical trials being the same, only adjustments generated by the different end-points used in various fields are needed to make these recommendations applicable to other medical specialties. The ultimate goal of this project is to increase the number of centers in CLR that participate in clinical trials, which will serve the patients and advance the science, thus benefiting the society in general.

\section{References}

1 Comis RL, Miller JD, Aldige CR, Krebs L, Stoval E: Public attitudes toward participation in cancer clinical trials. J Clin Oncol 2003;21:830-835.

2 Schwartsmann G: Breast cancer in South America: challenges to improve early detection and medical management of a public health problem. J Clin Oncol 2001;19:118S-124S. 